\title{
Assessment and Reporting of Driving Fitness in Patients with Dementia in Clinical Practice: Data from SveDem, the Swedish Dementia Registry
}

\author{
Joel Lovas ${ }^{\mathrm{a}}$, Seyed-Mohammad Fereshtehnejad ${ }^{\mathrm{b}, \mathrm{c}}$, Pavla Cermakova $^{\mathrm{a}, \mathrm{d}}$, Catarina Lundberg ${ }^{\mathrm{e}}$, \\ Björn Johansson $^{\mathrm{e}}$, Kurt Johansson ${ }^{\mathrm{e}}$, Bengt Winblad ${ }^{\mathrm{a}, \mathrm{f}}$, Maria Eriksdotter ${ }^{\mathrm{b}, \mathrm{f}}$ and Dorota Religa ${ }^{\mathrm{a}, \mathrm{f}, \mathrm{g}, *}$ \\ a Alzheimer's Disease Research Center, Division of Neurogeriatrics, Department of Neurobiology, Care Sciences \\ and Society (NVS), Karolinska Institutet, Stockholm, Sweden \\ ${ }^{\mathrm{b}}$ Division of Clinical Geriatrics, Department of Neurobiology, Care Sciences, and Society (NVS), Karolinska \\ Institutet, Stockholm, Sweden \\ ${ }^{\mathrm{c}}$ Department of Neurology and Neurosurgery, McGill University, Montreal General Hospital, Montreal, PQ, \\ Canada \\ ${ }^{\mathrm{d}}$ International Clinical Research Center and St.Anne's University Hospital, Brno, Czech Republic \\ ${ }^{\mathrm{e}}$ Traffic Medicine Centre, Karolinska University Hospital, Stockholm, Sweden \\ ${ }^{\mathrm{f}}$ Department of Geriatric Medicine, Karolinska University Hospital, Stockholm, Sweden \\ ${ }^{\mathrm{g}}$ Mossakowski Medical Research Centre Polish Academy of Sciences, Warsaw, Poland
}

\begin{abstract}
.
Background: Driving constitutes a very important aspect of daily life and is dependent on cognitive functions such as attention, visuo-spatial skills and memory, which are often compromised in dementia. Therefore, the driving fitness of patients with dementia needs to be addressed by physicians and those that are deemed unfit should not be allowed to continue driving.

Objective: We aimed at investigating to what extent physicians assess driving fitness in dementia patients and determinant factors for revoking of their licenses.

Methods: This study includes 15113 patients with newly diagnosed dementia and driver's license registered in the Swedish Dementia Registry (SveDem). The main outcomes were reporting to the licensing authority and making an agreement about driving eligibility with the patients.

Results: Physicians had not taken any action in $16 \%$ of dementia patients, whereas $9 \%$ were reported to the authority to have their licenses revoked. Males $(\mathrm{OR}=3.04)$, those with an MMSE score between 20-24 (OR = 1.35) and 10-19 (OR = 1.50), patients with frontotemporal $(\mathrm{OR}=3.09)$ and vascular dementia $(\mathrm{OR}=1.26)$ were more likely to be reported to the authority. Conclusion: For the majority of patients with dementia, driving fitness was assessed. Nevertheless, physicians did not address the issue in a sizeable proportion of dementia patients. Type of dementia, cognitive status, age, sex and burden of comorbidities are independent factors associated with the assessment of driving fitness in patients with dementia. Increased knowledge on how these factors relate to road safety may pave the way for more specific guidelines addressing the issue of driving in patients with dementia.
\end{abstract}

Keywords: Dementia, Alzheimer's disease, frontotemporal dementia, driving license, cognitive status, agreement

\footnotetext{
*Correspondence to: Dorota Religa, MD, PhD, Karolinska Institutet, NVS, Novum, plan 5, 14186 Stockholm, Sweden. Tel.: +46 08585000; E-mail: Dorota.Religa@ki.se.
} 


\section{INTRODUCTION}

Driving a car is one of the most frequently used means of transport among the elderly, allowing them independence in social participation and access to medical services [1]. With the continuously rising life expectancy and prevalence of age-related diseases [2], the number of older drivers affected by comorbidities is increasing [3]. This has raised concerns, since diseases that are more common in older age groups, such as dementia, contribute to poor driving and may increase the risk of car crashes $[3,4]$.

Driving is a complex task that requires a sufficient level of cognitive functioning in domains such as attention, visuo-spatial skills and memory $[5,6]$. These may be impaired in dementia, of which the most common underlying pathology is Alzheimer's disease (AD) [4, 7]. Lack of judgement that characterizes patients with frontotemporal dementia (FTD), and motor symptoms of patients with Parkinson's disease dementia (PDD) and dementia with Lewy bodies (DLB) may also impair driving ability [8, 9]. Moreover, cardiovascular comorbidities, common particularly in mixed and vascular dementia [10], can compromise one's the ability to drive safely [11].

Patients with dementia who are not fit to drive fitness should cease driving and be reported to authorities following appropriate assessments [12, 13]. It has been shown that physicians' warning to unfit drivers including the ones with cognitive impairment reduce the risk of subsequent crashes and road accidents [14]. Mandatory reporting could, however, jeopardize the relationship between doctors and patients [13]. According to the Swedish law, physicians should report patients who are unfit to drive to the licensing authority (at present the Swedish Transport Agency, STA), but may also reach an agreement with them to abstain from driving with them [15]. It is not known how the issue of driving capacity in dementia is addressed in clinical practice. Capitalizing on a nationwide registry of dementia patients, we aimed at investigating (1) the proportion and characteristics of patients that have been reported to the STA or have an agreement about refraining from driving and (2) factors associated with either reporting to the STA or reaching an agreement about driving or not taking an action at all. These findings could reflect the real-world clinical practice on the assessment of driving ability in patients with dementia and improve physicians' and caregivers' knowledge and attitude about this issue.

\section{METHODS}

We performed a cross-sectional study based on data from the Swedish Dementia Registry (SveDem). SveDem (www.svedem.se) is a national registry that was initiated in May 2007 with the aim to improve the care of patients with dementia; and has previously been described in detail [7].

\section{Ethical approval}

Participants received oral and written information regarding SveDem and its policies before registration and could decline to participate from start and at any time throughout the registration. In order to ensure privacy, data was treated confidentially, protected from unauthorized access and de-identified before analysis. The regional ethical review board in Stockholm granted a specific ethical permission for the present study (registration number 2013/832$31 / 1)$.

\section{Dementia diagnosis}

Dementia is diagnosed by a physician in a memory clinic or a primary care unit and classified as $\mathrm{AD}$, mixed dementia, vascular dementia, DLB, PDD, FTD, unspecified dementia or other types. The 10th revision of the International Classification of Disease criteria (ICD-10) [16], along with McKeith criteria [17] for DLB, the Lund-Manchester criteria [18] for FTD and the Movement Disorder Society Task Force criteria [19] for PDD are used.

\section{Driving fitness}

SveDem contains two variables with regard to driving cessation: whether the licensing authority has been informed regarding the patient's license holding and whether an agreement has been reached about driving a car. Possible answers are yes/no/don't know. We further use terms "reporting to the authority" for the first variable and "agreement about driving" for the second variable.

\section{Other variables}

At the time of dementia diagnosis, information on age, sex and Mini Mental State Examination (MMSE) score and total number of drugs is registered. Further variables concern living condition (own home / institution), co-residency (living alone 
/ living with another adult), use of day care and home care, registration unit (primary care / memory clinic) and medication (cholinesterase inhibitors, memantine, antidepressants, antipsychotics, anxiolytics, hypnotics and cardiovascular drugs). The total number of drugs is considered as a surrogate for overall comorbidity [20].

\section{Study sample}

From the total of 35995 patients registered into SveDem until December 2013, we excluded 6269 patients due to missing data regarding license status, 12322 patients who had no driver's license and 2002 patients with missing information on reporting to the agency or agreement about driving. Furthermore, we excluded 289 patients diagnosed with "other dementia types", resulting in the final sample of 15113 patients (Fig. 1).

\section{Statistical Analysis}

We calculated means [standard deviation (SD)] for continuous variables and frequencies (\%) for categorical variables. To compare characteristics between two groups (reporting to the agency vs. no reporting and agreement about driving vs. no agreement), we used Chi square tests for categorical variables and independent samples $t$ tests for continuous variables.

Binary logistic regression was applied to estimate odds ratios (OR) with $95 \%$ confidence intervals (CI) for associations of patients' characteristics with reporting to the agency and agreement about driving. We have presented three multivariate models, where patients' take away characteristics (age, sex, MMSE, dementia disorder and number of medications as a proxy for comorbidities) were independent variables and reporting to the agency (1st model), agreement about driving (2nd model) and no action at all (3rd

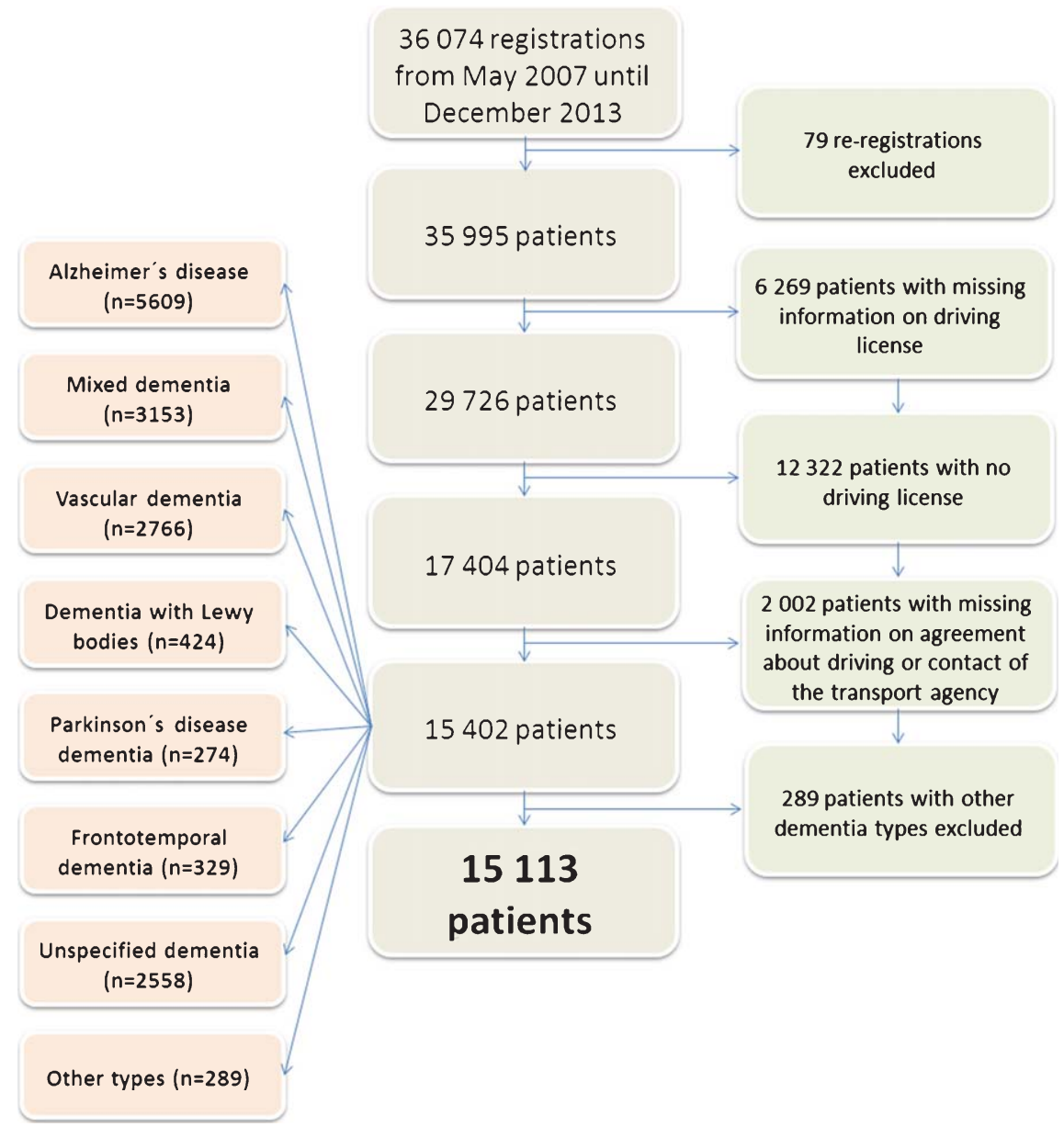

Fig. 1. Selection of the study population. 
model) were considered as dependent outcome variables in each model. Age, MMSE and number of drugs were used as categorical variables. All patients' characteristics were entered simultaneously into both models, which were also adjusted for the following information: living condition, co-residency, registration unit, day care, home care and medication (antidepressants, anxiolytics, antipsychotics, cardiovascular drugs and hypnotics).

Data was analyzed using SPSS software version 22 (IBM co., USA). The significance level was set at $<0.05$.

\section{RESULTS}

The study population consists of 15113 patients [mean age $=78(\mathrm{SD}=8)$ years, $56 \%$ males]. The most common dementia disorder was $\mathrm{AD}(37 \%)$, followed by mixed $(21 \%)$ and vascular dementia $(18 \%)$. The mean MMSE score at the time of dementia diagnosis was $22(\mathrm{SD}=5)$. Physicians reported 1359 patients (9\%) to the transport agency and had made an agree- ment about driving with 12513 patients (83\%). Fig. 2 presents how reporting to the agency and agreement about driving vary in subgroups of patients.

\section{Reporting to the agency}

Patients who were reported to the agency were more often men, were younger, had a slightly lower MMSE score and used less drugs compared to those who were not reported (Table 1). Diagnoses of vascular dementia and FTD were more common among those who were reported.

In multivariate analysis (Table 2), men were more likely to be reported than women $(\mathrm{OR}=3.04 ; 95 \%$ CI 2.62-3.52). The oldest patients ( $>85$ years) were the least likely to be reported $(\mathrm{OR}=0.42 ; 95 \% \mathrm{CI}$ 0.30-0.57). Compared to individuals with MMSE $\geq 25$, the odds of being reported was higher in those with an MMSE score between 20-24 (OR = 1.35; 95\% CI 1.17-1.56) and 10-19 (OR $=1.50 ; 95 \%$ CI 1.26-1.78). Patients using the highest number of drugs $(\geq 7)$ were the least likely to be reported
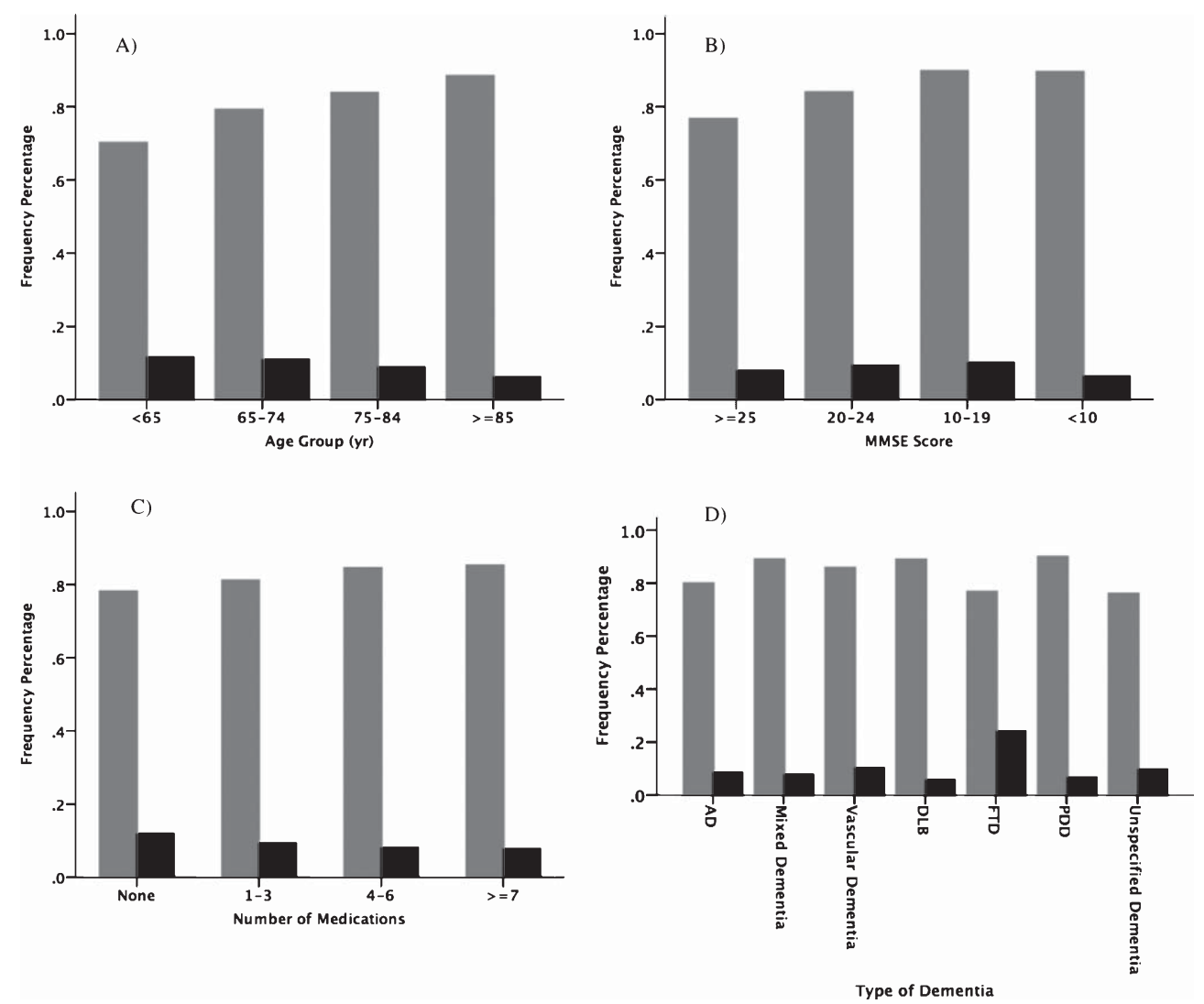

Fig. 2. Frequency of the agreement with drivers (grey bars) and reporting to the STA (black bars) in Swedish dementia patients with driving license with respect to age group (A), cognitive status (B), number of medications (C) and type of dementia disorder (D) $(n=15113)$. 
$(\mathrm{OR}=0.74 ; 95 \%$ CI 0.56-0.98). Compared to $\mathrm{AD}$, patients diagnosed with FTD $(\mathrm{OR}=3.09 ; 95 \% \mathrm{CI}$ $2.22-4.30)$ and vascular dementia $(\mathrm{OR}=1.26 ; 95 \%$ CI 1.05-1.51) were more likely to be reported, while the opposite was found for DLB (OR $=0.51 ; 95 \% \mathrm{CI}$ $0.32-0.81)$.

\section{Agreement about driving}

Patients who had an agreement about driving were less commonly men, were older, had a lower MMSE score and used more drugs, when compared to those who did not have an agreement (Table 1). The frequency of patients diagnosed with mixed dementia, vascular dementia, DLB and PDD was higher among those who had an agreement.

Multivariate analysis (Table 2) showed that men were less likely than women to have an agreement about driving ( $\mathrm{OR}=0.74,95 \%$ CI $0.67-0.82$ ). The highest likelihood of having an agreement was found in patients older than 85 years $(\mathrm{OR}=2.90 ; 95 \% \mathrm{CI}$ 2.31-3.63) and in patients with the MMSE score below $10(\mathrm{OR}=2.74 ; 95 \%$ CI 1.64-4.58). There was no association between total number of drugs and an agreement about driving. Diagnosis of mixed dementia, vascular dementia, DLB and PDD were associated with higher likelihood of agreement about driving when compared to AD.

\section{No action}

Physicians took no action to assess driving ability in 2449 dementia patients (16\%) with driving licenses. The likelihood of no action being taken was higher in men (OR $=1.23$; 95\% CI 1.11-1.37), while it was lower in older patients with lower MMSE score. Compared to those with $\mathrm{AD}$, patients with mixed dementia, vascular dementia, DLB or PDD were more likely to be assessed for driving ability (Table 2).

\section{DISCUSSION}

We found that physicians reported $9 \%$ of patients with dementia holding a driver's license to the authority. Reporting was associated with male sex, younger age, slightly lower global cognitive status, less comorbidity and in particular the diagnosis of FTD. Physicians had made an agreement about driving with $83 \%$ of patients with dementia. Coming to an agreement was associated with being female, older age, lower global cognitive status, a higher number of

Table 1

Characteristics of the study population $(n=15$ 113): Swedish Dementia Registry (SveDem), 2007-2013

\begin{tabular}{|c|c|c|c|c|c|c|}
\hline \multirow[t]{2}{*}{ Characteristic } & \multicolumn{3}{|c|}{ Reporting to the agency } & \multicolumn{3}{|c|}{ Agreement about driving } \\
\hline & Yes $(n=1359)$ & No $(n=13754)$ & $p$-value & Yes $(n=12513)$ & No $(n=2600)$ & $p$-value \\
\hline Men, $n(\%)$ & $1017(74.8)$ & $7397(53.8)$ & $<0.001$ & $6835(54.6)$ & $1579(60.7)$ & $<0.001$ \\
\hline Age, mean (SD) & $76.2(7.7)$ & $77.8(7.7)$ & $<0.001$ & $78.1(7.5)$ & $75.5(8.1)$ & $<0.001$ \\
\hline MMSE, mean (SD) & $21.8(4.5)$ & $22.1(4.7)$ & 0.012 & $21.8(4.7)$ & $23.5(4.2)$ & $<0.001$ \\
\hline Living in own home, $n(\%)$ & $1325(97.6)$ & $13136(95.6)$ & $<0.001$ & $11909(95.2)$ & $2552(98.3)$ & $<0.001$ \\
\hline Living alone, $n(\%)$ & $542(40.5)$ & $4941(36.7)$ & 0.006 & $4714(38.5)$ & $769(29.8)$ & $<0.001$ \\
\hline Day care, $n(\%)$ & $37(2.8)$ & $464(3.5)$ & 0.207 & $63(3.8)$ & $38(1.5)$ & $<0.001$ \\
\hline Home care, $n(\%)$ & $253(19.3)$ & $3208(23.9)$ & $<0.001$ & $3120(25.6)$ & $341(13.4)$ & $<0.001$ \\
\hline Registered at memory clinic, $n(\%)$ & $974(71.7)$ & $10324(75.1)$ & 0.022 & $9732(77.8)$ & $1566(60.2)$ & $<0.001$ \\
\hline \multicolumn{7}{|l|}{ Dementia disorder, n (\%) } \\
\hline Alzheimer's disease & $469(34.5)$ & $5140(37.4)$ & & $4495(35.9)$ & $1114(42.8)$ & \\
\hline Mixed dementia & $240(17.7)$ & $2913(21.2)$ & & $2813(22.5)$ & $340(13.1)$ & \\
\hline Vascular dementia & $282(20.8)$ & $2484(18.1)$ & & $2378(19.0)$ & $388(14.9)$ & \\
\hline Dementia with Lewy bodies & $24(1.8)$ & $400(2.9)$ & $<0.001$ & $378(3.0)$ & $46(1.8)$ & $<0.001$ \\
\hline Parkinson's disease dementia & $18(1.3)$ & $256(1.9)$ & & $247(2.0)$ & $27(1.0)$ & \\
\hline Frontotemporal dementia & $79(5.8)$ & $250(1.8)$ & & $253(2.0)$ & $76(2.9)$ & \\
\hline Unspecified type & $247(18.2)$ & $2311(16.8)$ & & $1949(15.6)$ & $609(23.4)$ & \\
\hline \multicolumn{7}{|l|}{ Medication, $n(\%)$} \\
\hline Cholinesterase inhibitors & $616(47.5)$ & $7245(53.8)$ & $<0.001$ & $6389(52.2)$ & $1472(58.5)$ & $<0.001$ \\
\hline NMDA-antagonists & $131(10.1)$ & $1336(10.0)$ & 0.823 & $1299(10.6)$ & $168(6.7)$ & $<0.001$ \\
\hline Antidepressants & $296(23.1)$ & $3643(27.4)$ & 0.001 & $3312(27.4)$ & $627(25.2)$ & $\mathbf{0 . 0 2 3}$ \\
\hline Antipsychotics & $72(5.6)$ & $603(4.5)$ & 0.082 & $586(4.8)$ & $89(3.6)$ & 0.006 \\
\hline Anxiolytics & $86(6.7)$ & $941(7.1)$ & 0.610 & $856(7.1)$ & $171(6.9)$ & 0.722 \\
\hline Hypnotics & $209(16.3)$ & $1819(13.7)$ & 0.009 & $1724(14.3)$ & $304(12.3)$ & 0.008 \\
\hline Cardiovascular drugs & $872(67.9)$ & $9186(68.9)$ & 0.472 & $8481(70.0)$ & $1577(63.2)$ & $<0.001$ \\
\hline Total number of medications mean (SD) & $4.0(2.9)$ & $4.4(3.1)$ & $<0.001$ & $4.5(3.1)$ & $4.0(3.0)$ & $<0.001$ \\
\hline
\end{tabular}

SD: standard deviation; $n$ : number; MMSE: mini-mental state examination. 
Table 2

Associations of patients' characteristics with the agreement about driving and reporting to the agency: Swedish Dementia Registry (SveDem), 2007-2013

\begin{tabular}{|c|c|c|c|c|c|c|}
\hline \multirow[t]{2}{*}{ Characteristic } & \multicolumn{2}{|c|}{ Reporting to the agency } & \multicolumn{2}{|c|}{ Agreement about driving } & \multicolumn{2}{|c|}{ No action } \\
\hline & OR $(95 \% \mathrm{CI})$ & $p$-value & OR $(95 \% \mathrm{CI})$ & $p$-value & OR $(95 \% \mathrm{CI})$ & $p$-value \\
\hline Male & $3.04(2.62-3.52)$ & $<0.001$ & $0.74(0.67-0.82)$ & $<0.001$ & $1.23(1.11-1.37)$ & $<0.001$ \\
\hline \multicolumn{7}{|l|}{ Age } \\
\hline$<65$ & 1 (Reference) & - & 1 (Reference) & - & 1 (Reference) & - \\
\hline $65-74$ & $1.04(0.80-1.35)$ & 0.774 & $1.58(1.31-1.90)$ & $<0.001$ & $0.65(0.54-0.78)$ & $<0.001$ \\
\hline $75-84$ & $0.76(0.59-0.98)$ & 0.033 & $2.18(1.81-2.61)$ & $<0.001$ & $0.46(0.38-0.56)$ & $<0.001$ \\
\hline$\geq 85$ & $0.42(0.30-0.57)$ & $<0.001$ & $2.90(2.31-3.63)$ & $<0.001$ & $0.36(0.29-0.46)$ & $<0.001$ \\
\hline \multicolumn{7}{|l|}{ MMSE } \\
\hline$\geq 25$ & 1 (Reference) & - & 1 (Reference) & - & 1 (Reference) & - \\
\hline $20-24$ & $1.35(1.17-1.56)$ & $<0.001$ & $1.54(1.39-1.71)$ & $<0.001$ & $0.62(0.56-0.69)$ & $<0.001$ \\
\hline $10-19$ & $1.50(1.26-1.78)$ & $<0.001$ & $2.53(2.19-2.92)$ & $<0.001$ & $0.36(0.31-0.42)$ & $<0.001$ \\
\hline$<10$ & $0.99(0.54-1.80)$ & 0.962 & $2.74(1.64-4.58)$ & $<0.001$ & $0.38(0.23-0.63)$ & $<0.001$ \\
\hline \multicolumn{7}{|l|}{ Total number of drugs } \\
\hline None & 1 (Reference) & - & 1 (Reference) & - & 1 (Reference) & - \\
\hline $1-3$ & $0.87(0.69-1.10)$ & 0.236 & $0.94(0.79-1.12)$ & 0.474 & $1.06(0.89-1.27)$ & 0.513 \\
\hline $4-6$ & $0.76(0.59-0.98)$ & 0.035 & $0.98(0.81-1.19)$ & 0.824 & $0.98(0.80-1.19)$ & 0.797 \\
\hline$\geq 7$ & $0.74(0.56-0.98)$ & $\mathbf{0 . 0 3 3}$ & $0.88(0.71-1.08)$ & 0.221 & $1.06(0.85-1.32)$ & 0.602 \\
\hline \multicolumn{7}{|l|}{ Dementia disorder } \\
\hline Alzheimer's disease & 1 (Reference) & - & 1 (Reference) & - & 1 (Reference) & - \\
\hline Mixed dementia & $0.97(0.81-1.16)$ & 0.727 & $1.65(1.43-1.91)$ & $<0.001$ & $0.60(0.52-0.70)$ & $<0.001$ \\
\hline Vascular dementia & $1.26(1.05-1.51)$ & 0.014 & $1.43(1.24-1.66)$ & $<0.001$ & $0.71(0.61-0.83)$ & $<0.001$ \\
\hline Dementia with Lewy bodies & $0.51(0.32-0.81)$ & 0.004 & $1.83(1.31-2.57)$ & $<0.001$ & $0.56(0.39-0.79)$ & 0.001 \\
\hline Parkinson's disease dementia & $0.66(0.38-1.14)$ & 0.136 & $2.09(1.35-3.22)$ & 0.001 & $0.52(0.33-0.80)$ & 0.003 \\
\hline Frontotemporal dementia & $3.09(2.22-4.30)$ & $<0.001$ & $0.91(0.67-1.24)$ & 0.558 & $0.86(0.62-1.20)$ & 0.376 \\
\hline Unspecified & $1.00(0.82-1.23)$ & 0.971 & $1.08(0.94-1.24)$ & 0.303 & $0.97(0.84-1.12)$ & 0.675 \\
\hline
\end{tabular}

OR: Odds ratio; CI: confidence interval; MMSE: Mini Mental State Examination. All variables in this table were entered simultaneously into both models. In addition, the models are adjusted for living condition, co-residency, registration unit, day care, home care and medication (antidepressants, anxiolytics, antipsychotics, cardiovascular drugs and hypnotics).

comorbid conditions and particularly with the diagnoses of DLB and PDD.

Patients who were reported to the STA were more often men, while those who had an agreement about driving were more likely to be women. As men are generally more often involved in car accidents [21], male drivers with dementia may be considered a bigger threat to road safety. We speculate that reaching an agreement about driving is more challenging with male patients, as elderly men may consider car driving as more important than do their female counterparts [21]. Female drivers tend to avoid dangerous traffic situations to a greater extent than men [22, 23 ], so women with dementia, if they have previously been active drivers, may likely stop driving of their own accord. On the other hand, physicians were more likely to take no action at all concerning younger-age males with $\mathrm{AD}$ and higher MMSE-scores.

Older drivers have a higher risk of being involved and dying in car accidents, but also have a tendency to self-restrict their driving [22]. This can explain why physicians tend to report younger patients to the authority. Our study showed that patients with MMSE score between 10 and 25 were more likely to be reported to the licensing authority when compared to those with MMSE above 25, while we did not detect any association for patients with MMSE lower than 10. Lower scores may be indicative of impaired driving, even though the correlation between MMSE score and driving performance is not strong [24]. We infer that patients with very severe cognitive impairment had already decided to give up driving, making reporting to the authority unnecessary. Moreover, this study indicates that patients who use higher numbers of drugs are less likely to be reported to the STA. As several comorbidities and drugs can contribute to poor driving ability $[25,26]$, we conclude that patients with a higher comorbidity burden restrict driving themselves.

FTD was the dementia subtype most commonly associated with reporting to the licensing authority. Their behavioral symptoms, such as lack of insight, agitation and disinhibition may pose a safety risk on the road [9] and also explain why they may not be willing to accept an agreement with a physician. On the other hand, DLB patients were the least likely to be reported. We hypothesized that symptoms such as hallucinations and motor impairment in DLB are 
severe enough to compromise driving ability, causing them to decide to give up driving. Moreover, PDD and DLB patients were more likely to have an agreement about driving compared to AD. We speculated that since they have more pronounced impairment in visual-spatial ability, attention and executive functions than AD patients [27], and that this correlates with their poor driving performance [28] physicians may pay more attention to driving in patients with PDD and DLB.

To our knowledge, this study is the first one to show how physicians address the issue of driving a car in a large population of patients with dementia in clinical practice. It is strengthened by a large sample size and inclusion of several dementia disorders. Diagnoses in SveDem are made in a clinical setting; however, their accuracy has not been examined since autopsy records are not available. Another limitation of this study is its cross-sectional design and possible residual confounding factors, such as patients' previous car crash history.

In conclusion, SveDem data demonstrated that for the in majority of dementia patients an agreement with the physician about their driving ability was reached and driving license was reported to authorities in about $9 \%$ of them. Nevertheless, physicians did not address the issue of driving in almost $16 \%$ of dementia patients who were more likely to be younger males a man with younger age suffering from AD with better cognitive status. Patients with FTD had an increased likelihood of being reported to the STA, while the opposite was observed for those with DLB. Other factors including age, sex, cognitive status and burden of comorbid conditions also seem to independently influence the choice of reporting a patient to the authority regarding driving capacity. This could be attributed to either the perceived crash risk, or the decreased likelihood of driving cessation related to these factors. Future studies are warranted in order to investigate the practical implications of our findings. Increased knowledge on how the factors identified in this study relate to road safety may pave the way for more specific guidelines addressing the issue of driving in patients with dementia.

\section{ACKNOWLEDGMENTS}

The authors are grateful to all patients, caregivers, physicians, data administrators and reporting units for providing information. The SveDem registry is supported by the Swedish Association of Local
Authorities and Regions and the Swedish Brain Power network. This study was supported by the Swedish Research Council.

\section{CONTRIBUTORS}

JL, SMF, PC, ME, BW and DR formulated the research question and designed the study. SMF, JL and $\mathrm{PC}$ analysed and interpreted the data, and drafted the manuscript. DR, ME, and BW interpreted the findings as well. DR, CL, BJ, and KJ contributed in data collection at the Traffic Medicine Centre. All authors reviewed the first draft and contributed in the final revision and approval of the final submitted manuscript.

\section{FUNDING}

This study was supported by the Swedish Research Council.

\section{REFERENCES}

[1] Martin AJ, Marottoli R, O'Neill D (2013) Driving assessment for maintaining mobility and safety in drivers with dementia. Cochrane Database Syst Rev 35.

[2] Christensen K, Doblhammer G, Rau R, Vaupel JW (2009) Ageing populations: The challenges ahead. Lancet 374, 1196-1208.

[3] Man-Son-Hing M, Marshall SC, Molnar FJ, Wilson KG (2007) Systematic review of driving risk and the efficacy of compensatory strategies in persons with dementia. $J \mathrm{Am}$ Geriatr Soc 55, 878-884.

[4] Eby DW, Silverstein NM, Molnar LJ, LeBlanc D, Adler G (2012) Driving behaviors in early stage dementia: A study using in-vehicle technology. Accid Anal Prev 49, 330-337.

[5] Dugan E, Barton KN, Coyle C, Lee CM (2013) US policies to enhance older driver safety: A systematic review of the literature. J Aging Soc Policy 25, 335-352.

[6] Dugan E, Lee CM (2013) Biopsychosocial risk factors for driving cessation: Findings from the Health and Retirement Study. J Aging Health 25, 1313-1328.

[7] Religa D, Fereshtehnejad SM, Cermakova P, Edlund AK, Garcia-Ptacek S, Granqvist N, Hallback A, Kawe K, Farahmand B, Kilander L, Mattsson UB, Nagga K, Nordstrom P, Wijk H, Wimo A, Winblad B, Eriksdotter M (2015) SveDem, the Swedish dementia registry - a tool for improving the quality of diagnostics, treatment and care of dementia patients in clinical practice in. PLoS One 10, e0116538.

[8] Crizzle AM, Classen S, Uc EY (2012) Parkinson disease and driving: An evidence-based review. Neurology 79, 2067 2074.

[9] Turk K, Dugan E (2014) Research brief: A literature review of frontotemporal dementia and driving. Am J Alzheimers Dis Other Demen 29, 404-408.

[10] Cermakova P, Fereshtehnejad SM, Johnell K, Winblad B, Eriksdotter M, Religa D (2014) Cardiovascular medication burden in dementia disorders: A nationwide study of 19,743 dementia patients in the Swedish Dementia Registry. Alzheimers Res Ther 6, 34 . 
[11] Kakaiya R, Fulkerson P (2000) Medical evaluation for driver qualification for patients with cardiovascular disorders. $J$ Am Board Fam Pract 13, 261-267.

[12] Johansson K, Lundberg C (1997) The 1994 International consensus conference on dementia and driving: A brief report. Swedish National Road Administration. Alzheimer Dis Assoc Disord 11(Suppl 1), 62-69.

[13] Rapoport MJ, Herrmann N, Molnar FJ, Man-Son-Hing M, Marshall SC, Shulman K, Naglie G (2007) Sharing the responsibility for assessing the risk of the driver with dementia. CMAJ 177, 599-601.

[14] Redelmeier DA, Yarnell CJ, Thiruchelvam D, Tibshirani RJ (2012) Physicians' warnings for unfit drivers and the risk of trauma from road crashes. N Engl J Med 367, 1228-1236.

[15] (1999) Fakta info direkt, Stockholm.

[16] WHO (1993) The ICD-10 Classification of Mental and Behavioral Disorders: Diagnostic Criteria for Research. Geneva, World Health Organization.

[17] McKeith IG, Dickson DW, Lowe J, Emre M, O'Brien JT, Feldman H, Cummings J, Duda JE, Lippa C, Perry EK, Aarsland D, Arai H, Ballard CG, Boeve B, Burn DJ, Costa D, Del Ser T, Dubois B, Galasko D, Gauthier S, Goetz CG, Gomez-Tortosa E, Halliday G, Hansen LA, Hardy J, Iwatsubo T, Kalaria RN, Kaufer D, Kenny RA, Korczyn A, Kosaka K, Lee VM, Lees A, Litvan I, Londos E, Lopez OL, Minoshima S, Mizuno Y, Molina JA, Mukaetova-Ladinska EB, Pasquier F, Perry RH, Schulz JB, Trojanowski JQ, Yamada M, Consortium on DLB (2005) Diagnosis and management of dementia with Lewy bodies: Third report of the DLB Consortium. Neurology 65, 1863-1872.

[18] (1994) Clinical and neuropathological criteria for frontotemporal dementia. The Lund and Manchester Groups. J Neurol Neurosurg Psychiatry 57, 416-418.

[19] Emre M, Aarsland D, Brown R, Burn DJ, Duyckaerts C, Mizuno Y, Broe GA, Cummings J, Dickson DW, Gauthier S, Goldman J, Goetz C, Korczyn A, Lees A, Levy R, Litvan I, McKeith I, Olanow W, Poewe W, Quinn N, Sampaio C,
Tolosa E, Dubois B (2007) Clinical diagnostic criteria for dementia associated with Parkinson's disease. Mov Disord 22, 1689-1707; quiz 1837.

[20] Schneeweiss S, Seeger JD, Maclure M, Wang PS, Avorn J, Glynn RJ (2001) Performance of comorbidity scores to control for confounding in epidemiologic studies using claims data. Am J Epidemiol 154, 854-864.

[21] Al-Balbissi AH (2003) Role of gender in road accidents. Traffic Inj Prev 4, 64-73.

[22] Herrmann N, Rapoport MJ, Sambrook R, Hebert R, McCracken P, Robillard A (2006) Predictors of driving cessation in mild-to-moderate dementia. Cmaj 175, 591-595.

[23] Seiler S, Schmidt H, Lechner A, Benke T, Sanin G, Ransmayr G, Lehner R, Dal-Bianco P, Santer P, Linortner P, Eggers C, Haider B, Uranues M, Marksteiner J, Leblhuber F, Kapeller P, Bancher C, Schmidt R, Group PS (2012) Driving cessation and dementia: Results of the prospective registry on dementia in Austria (PRODEM). PLoS One 7, e52710.

[24] Molnar FJ, Patel A, Marshall SC, Man-Son-Hing M, Wilson KG (2006) Clinical utility of office-based cognitive predictors of fitness to drive in persons with dementia: A systematic review. J Am Geriatr Soc, 54, 1809-1824.

[25] Transportstyrelsen (2013) Kristina Nilsson, Norrköping.

[26] Hetland A, Carr DB (2014) Medications and impaired driving. Ann Pharmacother 48, 494-506.

[27] McKeith IG, Rowan E, Askew K, Naidu A, Allan L, Barnett N, Lett D, Mosimann UP, Burn D, O’Brien JT (2006) More severe functional impairment in dementia with lewy bodies than Alzheimer disease is related to extrapyramidal motor dysfunction. Am J Geriatr Psychiatry 14, 582-588.

[28] Yamin S, Stinchcombe A, Gagnon S (2015) Driving competence in mild dementia with lewy bodies: In search of cognitive predictors using driving simulation. Int $J$ Alzheimers Dis 2015, 806024 